\title{
Etiology and Clinical Presentation of Laryngeal Cancer in Sudanese Patients
}

\begin{abstract}
Background: Laryngeal cancer is a common disease among Sudanese smokers. It is a type of neoplasm that has the largest male to female ratio in Sudan.
\end{abstract}

Objective: To provide a review of the clinical pattern and to determine the etiology of laryngeal cancer among the Sudanese patients.

Justification:-

- Cases of laryngeal cancer are increasing in Sudan.

- There were no publications regarding laryngeal cancer in Sudanese patients to my knowledge expect that reported by Sharfi 15 .

Methods: It was a prospective study, random sample, and cross sectional where 82 patients who were treated at Khartoum state hospitals during the period from March 2014 to Nov. 2016. Videolaryngoscopy, plain chest x-ray, CT-scan of the neck and thorax and Microlarynogoscopy studies were done to all patients.

Results: The larynx was examined with direct microlarynogoscopy for all patients. Laryngeal masses were found in the vocal cords. Biopsies confirmed the diagnoses.

Conclusion: Laryngeal cancer was common among Sudanese smoker patients and less common in non-smokers.

\section{Introduction}

Cancer of the larynx is ranked as the fourteenth most common cancer worldwide and it is the most common cancer in the head and neck [1]. Laryngeal cancer is a multifactorial disease, associated with a variety of lifestyle factors, environmental factor and smoking is the predominant risk factor for laryngeal cancer [2]. Most laryngeal cancers are squamous cell carcinomas [3-5]. Cancer can develop in any part of the larynx, and the majority can originate in the glottis, where the cure rate is affected by the location of the tumor and tumor staging $[1,6]$. The disease affects more men than women $[1,2,7]$; Laryngeal cancer at Mount Sinai Hospital [8]. Three-quarters of all diagnoses occur in patients older than 60 years [9]. The symptoms of laryngeal cancer depend on the size and location of the tumor. Symptoms may include the following: Hoarseness of voice, lump in the neck and stridor [1,2]. Etiology of laryngeal cancer includes; tobacco and alcohol are the most important etiological factors and most likely have a synergistic effect and also Human Papilloma Virus (HVP) [7]. Work-related exposure to substances such as nickel may also play a role in etiology [10]. There is no hereditary risk for squamous epithelial carcinoma in the larynx and smoking is the most important risk factor for laryngeal cancer [5]. Death from laryngeal cancer is 20 times more likely for heaviest smokers than for nonsmokers [11]. The disease caused by both genetic and environmental factors [12]. Besides, several other kinds of environmental factors, such as smoking and alcohol intake, human Papilloma virus infection and silica exposure

\section{International Journal of} Otorhinolaryngology

\author{
Sharfi Ahmed*, Abdelrhman S, Taha M, Malik M \\ and EI Naseh W
}

ORL head and neck surgery, University of Omdurman Islamic, Sudan

\section{*Address for Correspondence}

Sharfi Ahmed, ORL head and neck surgery, Faculty of medicine and health sciences, University of Omdurman Islamic Sudan, E-mail: doctorsharfi@gmail.com

Submission: 06 October, 2017

Accepted: 22 January, 2018

Published: 25 January, 2018

Copyright: ๑ 2018 Ahmed SA. This is an open access article distributed under the Creative Commons Attribution License, which permits unrestricted use, distribution, and reproduction in any medium, provided the original work is properly cited.

[13-15]. Some other quoted risk factors are likely, these include low socioeconomic status, male sex, and age greater than 55 years (SEER Stat Fact Sheets: Larynx Cancer) [6]. The combined consumption of alcohol and tobacco increases the laryngeal cancer risk in a synergistic (Laryngeal cancer at Mount Sinai Hospital). In females, we need to consider other habits in Sudan like the types of foods, smoking used for other purposes (Dokhan for smoothening complexion) and some other materials used for cleaning (clorex, etc) [16]. Diagnosis is made by doctor on the basis of medical history, physical examination, and special investigations which may include a chest $\mathrm{x}$-ray, CT or MRI scans, and tissue biopsy. It is the neoplasm with the largest male to female ratio in most populations. Thus, inadequate data is found in women [16]. The male to female sex ratio for laryngeal cancer is about 10:1 [17]. Trends over time in mortality were unremarkable for women as most published data reported in men [18]. Among few investigations providing data on women was a case-control study from the United States, including 56 females with the relative risk of 28.2 for smokers of $>20$ cigarettes/day compared with nonsmokers [19]. No data is found up to date related to African and Arab women [16]. Variations in laryngeal cancer incidence rates have been generally related to changes in tobacco and alcohol consumption. However, other relevant factors may be present among women [17]. Among these, diet may have a role in laryngeal carcinogenesis. Poor diet in fruits and fresh vegetables is associated with an increased laryngeal cancer risk [20]. Flexible endoscopy, possibly with loop laryngoscopy and direct microlaryngoscopy with biopsy. Fine needle cytology possibly with ultrasound [21,22]. Specific treatment depends on the location, type, and stage of the tumors. Treatment may involve surgery, radiotherapy, or chemotherapy, alone or in combination (Cancer - throat or larynx) [23].

\section{Materials and Methods}

This is a prospective study, cross sectional, random conducted at Khartoum state hospitals (Three ENT hospitals and four ENT units in general hospitals.) during the period from March 2014 to Nov 2016, 82 patients who were been diagnosed by the author as laryngeal carcinoma and included in the study where non-Sudanese were excluded. Following detailed history, general and local examination, 
Citation: Sharfi Ahmed, Abdelrhman S, Taha M, Malik M, El Naseh W. Etiology and Clinical Presentation of Laryngeal Cancer in Sudanese Patients. Inter J Otorhinolaryngology. 2018;5(1): 3.

ISSN: $2380-0569$

Table 1: Shows age and gender group $\mathrm{N}=82$.

\begin{tabular}{|c|c|c|c|}
\hline \multirow{2}{*}{ Age } & \multicolumn{2}{|c|}{ Gender } & \multirow{2}{*}{} \\
\cline { 2 - 3 } & Male & Female & \\
\hline $25-40$ & 2 & 2 & $4(4.9 \%)$ \\
\hline $41-60$ & 30 & 2 & $32(39 \%)$ \\
\hline More than 60 & 46 & 0 & $46(56.1 \%)$ \\
\hline Total & 78 & 4 & $82(100 \%)$ \\
\hline
\end{tabular}

$P . v=0.000$

Table 2: Shows smoking and gender $\mathrm{N}=82$.

\begin{tabular}{|c|c|c|c|}
\hline \multirow{2}{*}{ Smoking } & \multicolumn{2}{|c|}{ Gender } & \multirow{2}{*}{} \\
\cline { 2 - 3 } & Male & Female & \\
\hline Yes & $62(75.6 \%)$ & 0 & $62(75.6 \%)$ \\
\hline No & $16(19.5 \%)$ & $4(4.9 \%)$ & $20(24.4)$ \\
\hline Total & $78(95.1 \%)$ & $4(4.9 \%)$ & $82(100 \%)$ \\
\hline
\end{tabular}

P.v $=0.001$
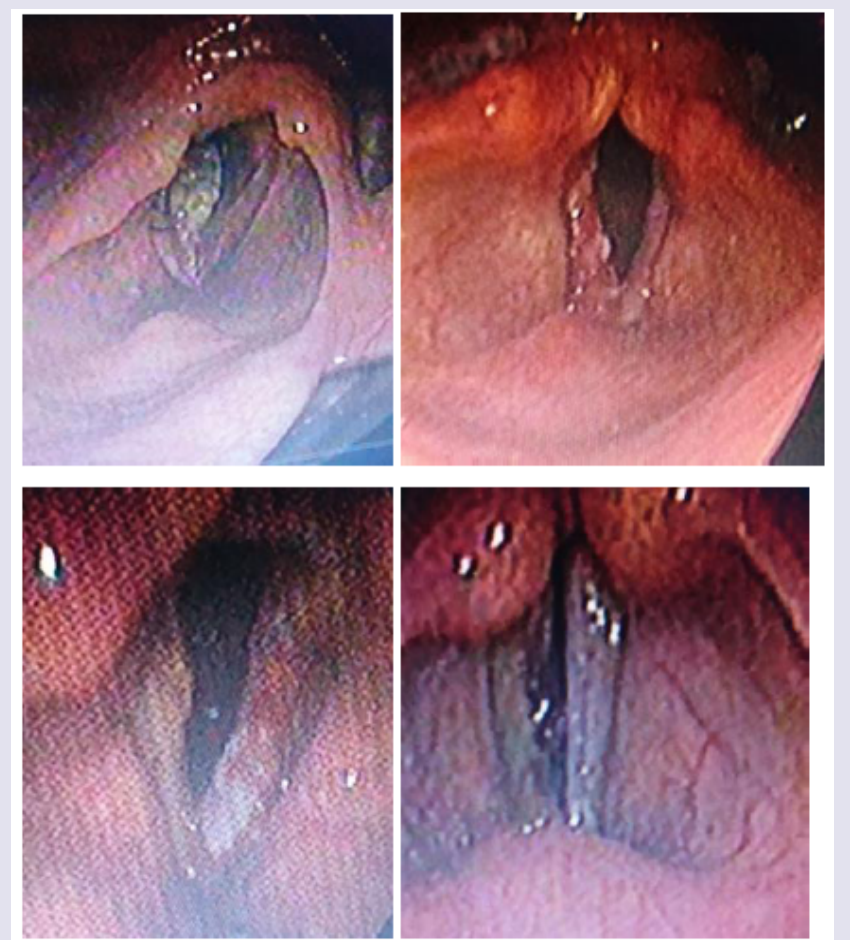

Figure 1: Some endoscopic photos of the patients with laryngeal cancer.

for all patients Video laryngoscopy was performed on the out patients clinic. Chest CT and CT/MRI of the neck and also flexible laryngoscopy were performed to all patients to exclude metastases. Direct laryngoscopy was done under general anesthesia and biopsies were taken from the laryngeal masses for histopathology.

\section{Data collection and management}

The data is collected using a carefully structured designed questionnaire by the author and experts filled in by the E.N.T surgeons directly on all patients, then analyzed through Statistical program. The patients were seen pre-and postoperatively and assessed clinically and endoscopically.

Ethical clearance
I explained verbally to the patients the aim of the study, data collection, and the need of investigations and regular follow up. All the patients have written consent, and the privacy of patients represents top priority to us. The hospital ethical committee approved the study.

\section{Results}

Table 1 shows that male gender were 95.1\% (78) cases while female were only 4 patients (4.9\%) and the disease was common in the age group more than 60 years of age and it accounted about 46 patients $(56.1 \%) p$ value (0.000). Regarding the relationship between age groups and gender the disease was common in more than 60 years male group (56.1\%) while it was less common in young age group between $25-40$ years old patients accounted about $4.9 \%$ in both male and female, $p$ value (0.000) (Table 1). Regarding the social history of the patients smoking was the commonest predisposing factor about $75.6 \%$.For smoking habit and gender; males were predominately $75.6 \%$ while females were $0 \% p$ value (0.000) (Table 2). The 4 females whom were found in this study were ranged in the age between 25-60 years old and they were not smokers, not alcohol takers, and did not confirmed important risk factors for women in Sudan as for men. $100 \%$ of patients presented with hoarseness of voice, few of them (20\%) were presented with stridor.

Regarding the histopathological type: all male patients 77 (93.9\%) had a squamous cell carcinoma of the larynx at glottis region except one patient who had a rare histopathology; botryoid sarcoma of the larynx1 (1.2\%). All female 4 (4.9\%) gender they had squamous cell carcinoma P.v=0.001 (Table 3). Only one patient (66 years old male) had botryoid sarcoma of the larynx (stage I) which it was a an embryonic type of sarcoma normally found in children at age of 3-8 years and rarely can affected adult male and larynx (Figure 1).

\section{Discussion}

It was a prospective study, random sample, and cross sectional where 82 patients who were treated at Khartoum state hospitals during the period from March 2014 to Nov 2016. Laryngeal cancer was common in Sudanese male (95.1\%) and this in agreement with most of the published literatures [11,17,9]. Smoking and alcohol consumptions were the commonest predisposing factors and also this was elicited by all authors in the literature $[1,11,7,17,19]$. All patients presented with hoarse voice (100\%) this agrees with Sadri M and Villanueva-Reyes A $[6,24]$.

With reference to diet, there was a study that provided additional evidence that vegetables, olive oil, and perhaps fresh fruit have a favorable effect on laryngeal cancer $[6,24,25]$. Study was done about several reproductive and hormonal factors, none of which was, however, strongly related to laryngeal cancer risk $[25,13]$. However, given the rarity of the disease in women, the study had a relatively low power to detect associations with these factors. In terms of population attributable risk, tobacco smoking accounted for $78 \%$

Table 3: The histopathological type and gender $\mathrm{N}=82$.

\begin{tabular}{|c|c|c|c|}
\hline \multirow{2}{*}{ Histopathology } & \multicolumn{2}{|c|}{ Gender } & \multirow{2}{*}{$\%$} \\
\cline { 2 - 3 } & Male & Female & \\
\hline Squamous cell carcinoma & $77(93.9 \%)$ & $4(4.9 \%)$ & $81(98.8 \%)$ \\
\hline Botryoid sarcoma & $1(1.2 \%)$ & 0 & $1(1.2)$ \\
\hline Total & $78(95.1 \%)$ & $4(4.9 \%)$ & $82(100 \%)$ \\
\hline P.v $=0.001 \quad$ & & \\
\hline
\end{tabular}


Citation: Sharfi Ahmed, Abdelrhman S, Taha M, Malik M, El Naseh W. Etiology and Clinical Presentation of Laryngeal Cancer in Sudanese Patients. Inter J Otorhinolaryngology. 2018;5(1): 3.

of laryngeal cancer, alcohol drinking for $34 \%$, and the combination of the two factors together account 6 for $82 \%$. Low vegetable intake was estimated as a risk in $30 \%$ and for the combination of alcohol, tobacco, and low vegetables diet were estimated as a risk in $85 \%$ of the cases of laryngeal cancer $[6,24,25]$. The question is to identify the predisposing factors of laryngeal carcinomas in Sudan.

Diagnosis was made by different methods which includes, CT/ MRI Neck, Flexible loop laryngoscopy and direct microlaryngoscopy also these methods were used by Wittekind C and othrs $[1,2,22,16]$. Squamous cell carcinoma was the commonest histopathological type and this goes with Mork J et al. result and other authors [1,2,5]. With regard to the rare case in this study: the 66 years old male who had a botryoid sarcoma of the larynx, the disease used to be uniformly fatal, with a 5 years survival rate between 10 and 35\% [21]. Unfortunately the patient died immediately (2weeks) post Radiochemotherapy sessions [26-28].

\section{Conclusion}

- Laryngeal cancer was common in Sudanese male smokers over 55 years old.

- Significant differences in sex were observed, it also appeared recently in females.

- Diagnosis was made by direct laryngoscopy and confirmed histopathologically, and Squamous cell carcinoma was the commonest type.

- We need to consider other habits in Sudan like the types of foods, smoking used for other purposes and some materials uses for cleaning (clorex, etc).

\section{References}

1. Villanueva-Reyes A, Strand E, Nazario CM, Irizarry-Ramirez M (2008) Cancer of the larynx in Puerto Rico. P R Health Sci J 27: 196-203.

2. Sadri M, McMahon J, Parker A (2006) Laryngeal dysplasia: aetiology and molecular biology. J Laryngol Otol 120: 170-177.

3. Boysen M, Lövdal O, Tausjö J, Winther F (1992) The value of follow-up in patients treated for squamous cell carcinoma of the head and neck. Eur $\mathrm{J}$ Cancer 28: 455-460.

4. Mirisola V, Mora R, Esposito Al, Guastini L, Tabacchiera F, et al. (2011) "A prognostic multigene classifier for squamous cell carcinomas of the larynx". Cancer Lett 307: 37-46.

5. Mork J, Møller B, Glattre E (1999) Familial risk in head and neck squamous cell carcinoma diagnosed before the age of 45: a population based study. Oral Oncol 35: 360-367.

6. (2014) "SEER Stat Fact Sheets: Larynx Cancer". NCI.

7. Thawley SE, Panje WR, Batsakis JG, Lindberg WB (1999) Comprehensive management of head and neck tumors. $2^{\text {nd }}(E d n)$. In: Opplag WB Philadelphia: saunders company.
8. Laryngeal cancer at Mount Sinai Hospital.

9. Jones TM, De M, Foran B, Harrington K, Mortimore S (2016) Laryngea cancer: United Kingdom National Multidisciplinary guidelines. J Laryngol Otol 130: S75-S82.

10. Pedersen E, Høgetveit AC, Andersen $\AA$ (1973) Cancer of respiratory organs among workers at a nickel refinery in Norway. Int $\mathrm{J}$ Cancer 12: 32-41.

11. Ridge JA, Glisson BS, Lango MN, et al. 2008 "Head and Neck Tumors". In: Pazdur R, Wagman LD, Camphausen KA, Hoskins WJ (Eds.) Cancer Management: A Multidisciplinary Approach. (11 th $E d n)$.

12. Brockmoller J, Cascorbi I, Henning S, Meisel C, Roots I (2000) Molecular genetics of cancer susceptibility. Pharmacology 61: 212-227.

13. La Vecchia C, Zhang ZF, Altieri A (2008) Alcohol and laryngeal cancer: an update. Eur J Cancer Prev 17:116-124.

14. Poljak M, Seme K, Maver PJ, Kocjan BJ, Cuschieri KS, et al. (2013) Human papillomavirus prevalence and type-distribution, cervical cancer screening practices and current status of vaccination implementation in Central and Eastern Europe. Vaccine 31: H59-H70.

15. Chen M, Tse LA (2012) Laryngeal cancer and silica dust exposure: a systematic review and meta-analysis. Am J Ind Med 55: 669-676.

16. Sharfi AO (2012) Laryngeal cancer in Sudanese women. Sudan JMS 7: 201 204.

17. Levi F, La Vecchia C, Lucchini F, Negri E (1992) Trends in cancer mortality sex ratios in Europe, 1950!1989. World Health Stat Q 45: 117-164.

18. Lucchini F, Negri E, Boyle P, La Vecchia C (1999) Cancer mortality in Europe, 1990 !1994, and an overview of trends from 1955 to 1994. Eur J Cancer 35: 1477-1516.

19. Wynder EL, Covey LS, Mabuchi K, Mushinski M (1976) Environmental factors in cancer of the larynx: a second look. Cancer 38: 1591-1601.

20. Tavani A, Negri E, Franceschi S, Barbone F, La Vecchia C (1994) Attributable risk for laryngeal cancer in Northern Italy. Cancer Epidemiol Biomark Prev 3: 121-125.

21. Sobin LH, Wittekind C (2002) (Eds.). TNM Classification of Malignant Tumours. (6 $6^{\text {th }}$ Edn). New York: Wiley-Liss.

22. Wittekind C, Greene FL, Hutter RVP, Klimpfinger M, Sobin LH (2005) TNM Atlas. ( $5^{\text {th }}$ edn). Heidelberg.

23. Cancer - throat or larynx, Medline plus medical encyclopedia.

24. Abenstein H, Nordgren M, Boysen M, Jannert M, Sllander E, et al. (2005) Quality of life and head and neck cancer: a 5 year prospective study. Laryngoscope 115: 2183-2192.

25. Hilgers RD (1975) Pelvic exenteration for vaginal emboryonal rhabdomyosarcoma; a review. Obstet Gynecol 45: 175-180.

26. Mahler V, Brøndbo K, Boysen M (2010) Radiotherapy or $\mathrm{CO}_{2}$ laser surgery as treatment of $T_{1}$ glottic carcinoma? Eur Arch Otolaryngol. In press 267: 743-750.

27. Vermund H, Boysen M, Evensen JF, Jacobsen AB, Natvig K, et al. (1998) Recurrence after different primary treatment for cancer of the supraglottic larynx. Acta Oncol 37: 167-173.

28. Franceschi S, Bidoli E, Negri E, Barbone F, La Vecchia C (1994) Alcohol and cancers of the upper aerodigestive tract in men and women. Cancer Epidemiol Biomark Prev 3: 299-304. 